\title{
Analysis on the Development of International Logistics Management Based on Bibliometrics
}

\author{
Huang Jin; Liu Xuan*, Zhang Rong; He Yihua; Wei Fengping; Fang Ji; Liu Chang \\ Library of Huazhong University of Science and Technology \\ Wuhan, Hubei, China \\ hjhust@hust.edu.cn; *liuxuan@hust.edu.cn
}

\begin{abstract}
This paper explores 20,555 papers embodied by SCI-EXPANDED, SSCI, A\&HCI, CPCI-S and CPCI-SSH in the past 10 years. We compared and analyzed the increasing trend, research institutions, research field, and subject distributions. The global logistics management research papers are fluctuating up; Chinese logistics research is in the forefront of the papers published while the United States have the highest citation frequency and have the highest overall research level and institutional level; All the paper are concentrated in several disciplines such as operation and optimization. Based on the analysis of word frequency, the key words are extracted more than 1000 times, it identifies that logistics research is formed into four knowledge groups: logistics, supply chain, management, logistics technology.
\end{abstract}

Keywords-Logistics; Logistics Research; Knowledge Groups; Bibliometric Analysis

\section{INTRODUCTION}

Modern logistics is the foundation of the national economy, the level of a country's logistics development has become an important benchmark to measure the level of its economic development [1]. At present, logistics management related research has received extensive attention, the majority of scholars and practitioners use different methods to study the formation of many research results. From a different point of view, these studies reflect the focus of current research and the focus of logistics management. These studies have different direction of application fields and different research methods. In order to further understand the current situation of logistics management research and scientifically analyze the current situation of logistics management research, and benefit the future research, this paper will use the method of bibliometric analysis to study and analyze the above problems.

\section{Data Sources AND Research Methods}

\section{A. Data sources}

Data source: Web of Science platform. Web of Science information retrieval platform can search for high quality documents on natural Sciences, social sciences, arts and humanities. Search strategy: "logistics" for the theme of retrieval. Time range: from 2007 to 2016 (deadline December 31 , 2016) a total of 10 years. Because of the rapid development of research in the field of logistics, in order to spread the latest research faster, there is a lot of high-quality literatures published in the form of conference papers. Therefore, the scope of the search is defined as the following 5 databases: SCI-EXPANDED, SSCI, A\&HCI, CPCI-S, CPCI$\mathrm{SSH}$, and the document type are article, review, proceedings papers. We retrieved a total of 20,555 papers on the logistics field. We downloaded all papers bibliographic data and characterized by merging and cleaning.

\section{B. Research methods and analytical tools}

Bibliometric analysis is a way to understand the present situation and development trend of research from the macro point of view [2]. From the literature point of view, it summarizes the development trend of the research field, the core institutions, research hot spots, etc., which can make people quickly have a general understanding of the whole picture in the field of research and provide macro reference for the relevant departments to carry out the research work in the future. The analysis tools used in this study: WOS platform, Thomson Data Analyzer (TDA) software, UCINET software.

\section{Analysis of posting quantity of Logistics Management}

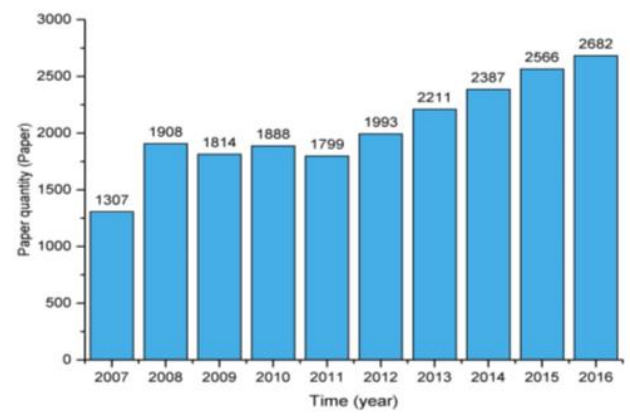

Fig. 1. The Change of the Number of Research Papers on Logistics Management

The general trend of the paper can be observed from the time and number of papers distribution. From figure 1, during the period of 2007-2016, the world's research papers on Logistics Management show fluctuating upward trend. Among them, the number of 2007 papers is relatively small, accounting for 1307. In 2008, the number of maximum growth relative to the previous year, rose $45.98 \%$. The number of papers remained stable from 2008 to 2011, and since 2012, the 
number of papers has been increasing year by year, reaching 2686 by the highest peak in 2016

\section{RESEARCH CAPACITY DISTRIBUTION AND COMPARATIVE ANALYSIS OF LOGISTICS MANAGEMENT}

\section{A. Research Capacity Distribution}

1) Analysis of distribution of research countries and regions

The number of papers published in a country (or region) could indicate to some extent the degree of attention to the field of research of the country (or region).The more the number of academic papers published, the more attention is paid to the study of the subject. According to all the authors of their corresponding countries and regions for analysis, the main countries and regions which research logistics management in the global are China, the United States, Germany, Britain, Canada, Italy, France, New Zealand, China Taiwan, Spain and so on. From Table 1, over the past 10 years (2007-2016) China's research in this field is becoming more and more active, the number of papers is 6853, and accounting for $41.99 \%$ of all national papers, which is about 2 times the United State ranked second. As can be seen from Table 1, the citation frequency of the United States published papers is the highest, followed by the United Kingdom. China published papers total citation frequency is ranked third, but the average citation frequency is low.

TABLE I. PUBLISHEd PAPERS AND CITATION FREQUENCY

\begin{tabular}{|l|r|r|r|}
\hline Country / Region & Papers & $\begin{array}{c}\text { Citation } \\
\text { Frequency }\end{array}$ & $\begin{array}{c}\text { Average } \\
\text { Quoting Rate }\end{array}$ \\
\hline $\begin{array}{l}\text { PEOPLES R } \\
\text { CHINA }\end{array}$ & 6853 & 10835 & 1.58 \\
\hline USA & 3551 & 37570 & 10.58 \\
\hline GERMANY & 1464 & 9695 & 6.62 \\
\hline ENGLAND & 922 & 10975 & 11.90 \\
\hline CANADA & 642 & 8826 & 13.75 \\
\hline ITALY & 625 & 4663 & 7.46 \\
\hline FRANCE & 583 & 5650 & 9.69 \\
\hline NETHERLANDS & 574 & 6883 & 11.99 \\
\hline TAIWAN & 571 & 4541 & 7.95 \\
\hline SPAIN & 535 & 4191 & 7.83 \\
\hline
\end{tabular}

\section{2) Distribution of Core Research Institutions}

Important research institutions which have a strong representation of scientific research, they play a leading role in the direction of discipline development. The published papers and citations of research institutions are counted with standardization of all research institutions names and merging repetitive institutions, and ranked according to the number and frequency of citation respectively. Table 2 lists the number of papers and the cited frequency of 20 research institutions with largest number of published papers and rank them according to the number of papers and citations. In the top 20 institutions, 6 belong to China, 8 belong to the United States, 2 belong to
Singapore, and the other 4 belong to Germany, France, Canada and the United Kingdom. In the top 20 institutions, Beijing Jiaotong University and Wuhan University of Technology have more than 200 papers, Hong Kong Polytech University have about 200 papers, California university system, University of Georgia system and the University of Florida system have papers between 150 and 200.Judging from the past 10 years, Beijing Jiaotong University, Wuhan University of Technology, Hong Kong Polytech University, California university system, University of Georgia system and University of Florida system have very active research performance in this field, and the papers are accounted for $15.31 \%, 9.51 \%, 6.82 \%, 6.08 \%, 5.69 \%$ and $5.37 \%$ respectively, the remaining 14 institutions accounted for $51.22 \%$ of papers.

TABLE II. The Number Of Published PAPERs ANd Citation FREQUENCY OF THE MAIN INSTITUTIONS

\begin{tabular}{|c|c|c|c|}
\hline Institution & Papers & $\begin{array}{c}\text { Citation } \\
\text { Frequency }\end{array}$ & Country \\
\hline Beijing Jiaotong University & 433 & 379 & $\begin{array}{l}\text { CHINA } \\
\text { MAINLAND }\end{array}$ \\
\hline $\begin{array}{l}\text { Wuhan University of } \\
\text { Technology }\end{array}$ & 269 & 79 & $\begin{array}{l}\text { CHINA } \\
\text { MAINLAND }\end{array}$ \\
\hline $\begin{array}{l}\text { Hong Kong Polytechnic } \\
\text { University }\end{array}$ & 193 & 2537 & $\begin{array}{l}\text { CHINA } \\
\text { HONG KONG }\end{array}$ \\
\hline University of California System & 172 & 1901 & USA \\
\hline University System of Georgia & 161 & 2599 & USA \\
\hline $\begin{array}{l}\text { State University System of } \\
\text { Florida }\end{array}$ & 152 & 1480 & USA \\
\hline University of Bremen & 130 & 533 & GERMANY \\
\hline $\begin{array}{l}\text { South China University of } \\
\text { Technology }\end{array}$ & 123 & 94 & $\begin{array}{l}\text { CHINA } \\
\text { MAINLAND }\end{array}$ \\
\hline $\begin{array}{l}\text { Pennsylvania Commonwealth } \\
\text { System of Higher Education } \\
\text { (PCSHE) }\end{array}$ & 116 & 1098 & USA \\
\hline $\begin{array}{l}\text { United States Department of } \\
\text { Defense }\end{array}$ & 116 & 917 & USA \\
\hline $\begin{array}{l}\text { Centre National de la } \\
\text { Recherche Scientifique } \\
\text { (CNRS) }\end{array}$ & 112 & 905 & FRANCE \\
\hline Shanghai Maritime University & 109 & 121 & $\begin{array}{l}\text { CHINA } \\
\text { MAINLAND }\end{array}$ \\
\hline $\begin{array}{l}\text { Huazhong University of } \\
\text { Science \& Technology }\end{array}$ & 107 & 343 & $\begin{array}{l}\text { CHINA } \\
\text { MAINLAND }\end{array}$ \\
\hline University of Montreal & 104 & 1609 & CANADA \\
\hline $\begin{array}{l}\text { Georgia Institute of } \\
\text { Technology }\end{array}$ & 91 & 1629 & USA \\
\hline $\begin{array}{l}\text { University of Tennessee } \\
\text { System }\end{array}$ & 91 & 1568 & USA \\
\hline $\begin{array}{l}\text { Nanyang Technological } \\
\text { University } \\
\end{array}$ & 88 & 1161 & SINGAPORE \\
\hline $\begin{array}{l}\text { Nanyang Technological } \\
\text { University \& National Institute } \\
\text { of Education (NIE) Singapore }\end{array}$ & 88 & 1161 & SINGAPORE \\
\hline
\end{tabular}




\begin{tabular}{|l|c|c|l|}
\hline \multicolumn{4}{|c|}{ TABLE 2, cont. } \\
\hline $\begin{array}{l}\text { University of Tennessee } \\
\text { Knoxville }\end{array}$ & 87 & 1539 & USA \\
\hline University of London & 87 & 1311 & ENGLAND \\
\hline
\end{tabular}

\section{B. Comparative Analysis of Research Capacity}

All the time, the number of papers and citation frequency are two important aspects of the analysis of the quality of the research results, which can reflect the strength and influence of researchers to a large extent [3]. Figure 2 and Figure 3 are the relative positions of the quadrant of the point of view, which compare the research power of major countries/regions and institutions respectively. The paper number of major countries/regions or institutions is shown on horizontal axis and the vertical axis is the citation frequency of the papers issued by each of them, the origin of the coordinates is the average value of papers and citation frequency. When the country/region or institution is located in the first quadrant, it shows that the number of papers and citations are higher than average, which can illustrate that the research has a high quality and quantity, while the third quadrant is the opposite; When the country/regional or institution is located in second quadrant, which can illustrate that the number of papers is lower than the average, but the citation frequency is higher than the average, while the fourth quadrant is the opposite.

As can be seen from Figure 2 and Figure 3, the United States, the United Kingdom and Canada, are located in the first and second quadrants both at the national level and at the institutional level, indicating that the overall level of research and institutional level in these countries are very strong. For China and its research institutions that are very active in recent years, only appeared in the third quadrant and the fourth quadrant, which indicates that its future research should not only focus on the number of papers published, but also to pay attention to the influence of the paper, increase its world recognized degree.

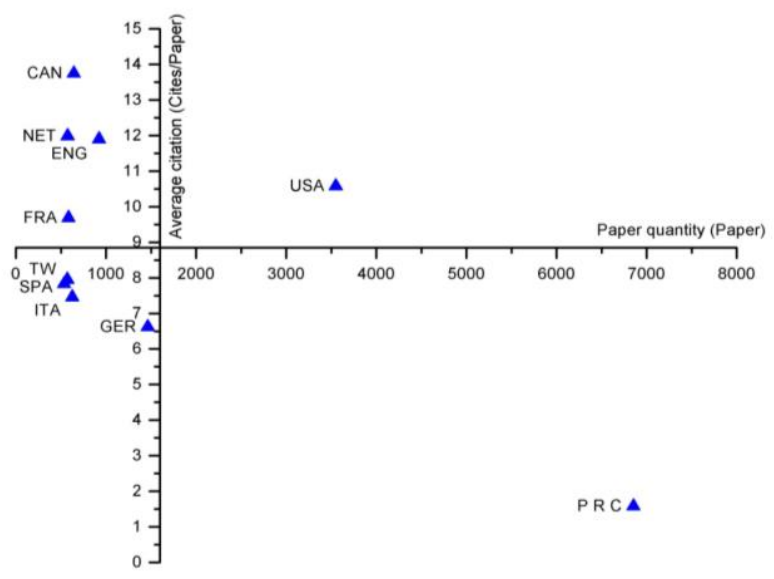

Fig. 2. Analysis of research results in major countries

\section{ThE RESEARCH DiRECTION AND SUBJECT ANALYSIS}

According to the classification of WOS database on a specific research field, table 3 lists the top 20 specific research directions of international logistics management research papers in accordance with the number of papers. As can be seen from table 3, the top 5 research directions were: OPERATIONS RESEARCH MANAGEMENT SCIENCE (4944), MANAGEMENT (3924) ENGINEERING INDUSTRIAL (2573), ENGINEERING ELECTRICAL ELECTRONIC (2258), COMPUTER SCIENCE INFORMATION SYSTEMS (1807). The above 5 research directions, the first two directions are more biased with theoretical methods, and the latter three directions are more biased with engineering applications. This shows that the theoretical research is much more than the methods research in international logistics management area.

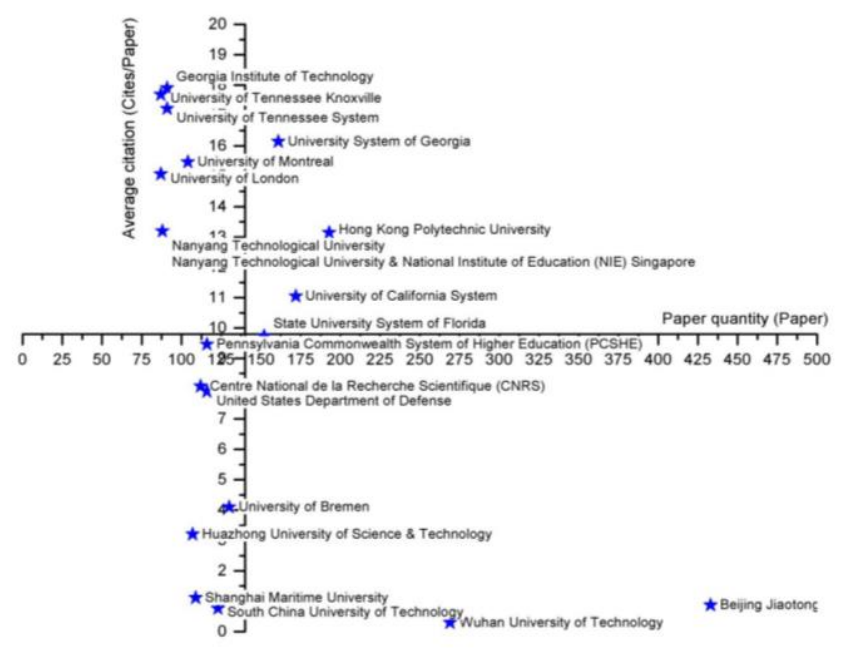

Fig. 3. Analysis of the research results of core institutions

TABLE III. INTERNATIONAL LOGISTICS MANAGEMENT RESEARCH FIELD AND RESEARCH DIRECTIONS

\begin{tabular}{|l|l|l|}
\hline No. & \multicolumn{1}{|c|}{ Web of Science Research Directions } & $\begin{array}{l}\text { Numbe } \\
\text { r }\end{array}$ \\
\hline 1 & $\begin{array}{l}\text { OPERATIONS RESEARCH MANAGEMENT } \\
\text { SCIENCE }\end{array}$ & 4944 \\
\hline 2 & MANAGEMENT & 3924 \\
\hline 3 & ENGINEERING INDUSTRIAL & 2573 \\
\hline 4 & ENGINEERING ELECTRICAL ELECTRONIC & 2258 \\
\hline 5 & $\begin{array}{l}\text { COMPUTER SCIENCE INFORMATION } \\
\text { SYSTEMS }\end{array}$ & 1807 \\
\hline 6 & $\begin{array}{l}\text { COMPUTER SCIENCE INTERDISCIPLINARY } \\
\text { APPLICATIONS }\end{array}$ & 1776 \\
\hline 7 & BUSINESS & 1644 \\
\hline 8 & ENGINEERING MANUFACTURING & 1600 \\
\hline 9 & COMPUTER SCIENCE THEORY METHODS & 1508 \\
\hline 10 & ECONOMICS & 1459 \\
\hline 11 & $\begin{array}{l}\text { COMPUTER SCIENCE ARTIFICIAL } \\
\text { INTELLIGENCE }\end{array}$ & 1348 \\
\hline 12 & TRANSPORTATION & 1222 \\
\hline 13 & TRANSPORTATION SCIENCE TECHNOLOGY & 1163 \\
\hline 14 & AUTOMATION CONTROL SYSTEMS & 1049 \\
\hline 15 & ENGINEERING MECHANICAL & 821 \\
\hline 16 & ENGINEERING MULTIDISCIPLINARY & 770 \\
\hline 17 & ENGINEERING CIVIL & 675 \\
\hline
\end{tabular}




\begin{tabular}{|l|l|l|}
\hline \multicolumn{3}{|c|}{ TABLE 3, cont. } \\
\hline 18 & MATERIALS SCIENCE MULTIDISCIPLINARY & 654 \\
\hline 19 & ENVIRONMENTAL SCIENCES & 650 \\
\hline 20 & TELECOMMUNICATIONS & 600 \\
\hline
\end{tabular}

Extracted the key words from the global 20555 papers published in 2007-2016 in the logistics management, a total of 7902 key words whose cumulative frequency of the occurrence is 672277 times. The keywords frequency is the total number of keywords in all the key words of the paper [4].

The maximum frequency of the keywords "logistic" is the occurrence frequency of 14850 times, which means that there are 14850 papers using the key words, others key words that appears more than 2000 times were "supply chain", "reverse logistics", "supply chain management", "city logistics", "optimization", "sustainability", "simulation", "humanitarian logistics". See table 4.

Based on the word frequency statistics of the paper keywords in 2007-2016, we analyze the knowledge community in this field:

1) Logistics knowledge group: V1 logistics, V3 reverse logistics, V5 city logistics, V9 humanitarian logistics, V 16 green logistics, V 21 urban logistics and V23 biomass logistics were included. These keywords cover the hot spot in the field of logistics, in addition to concern the very high degree of city logistics and reverse logistics, a new concern also reflects the new direction of the development of logistics, such as biomass derived from green logistics. The goal of biomass and green logistics is to reduce environmental pollution and reduce resource consumption, and it is not only an important part of circular economy, but also a part of protecting the ecological environment of the earth for the effective mode of realizing sustainable development [5]. Humanitarian logistics is caused by sudden natural disasters, local military conflicts and other unexpected factors of logistics activities; it has high demands on collaborative mechanism of lean and agile rescue process in the relief process, which belongs to the new comprehensive department of the cross between the logistics management and disaster management [6].

2) Supply Chain Management Group: including V2 supply chain, V4 supply chain management, V19 closed-loop supply chain, V27 facility location. Supply chain is the core research hotspot in logistics research, it constructs the supply chain network from the industrial level and combines the research method of model construction, analyzes the industrial development in specific areas and relies on the strategic alliance of contract. At the same time, it is also the most critical "bridge" that links to other knowledge points, for example, combination of closed-loop supply chain and reverse logistics is an important means which can solve the energy crisis and reduce environmental pollution, its economic value is more and more prominent [7].

3) Logistics management knowledge group: including V6 e-commerce, V12 internet of things, V13 management, V24 remanufacturing, V26 collaboration, V28 risk management.
With the progress of Internet and information technology, the whole process of logistics optimization and integration continue to accelerate, improving the level of logistics management is essential to enhance the competitiveness of enterprises. Risk management has also become an important guarantee to ensure the smooth operation of the logistics in a rapidly changing competitive environment.

4) Logistics technology knowledge group: including V6 optimization, V7 sustainability, V8 simulation, V10 genetic algorithm, V14 transportation, V15 model, V17 performance, V18 RFID, V22 vehicle routing. The knowledge group mainly uses the cybernetics method, simulation modeling method, mathematical programming and optimization method, uses radio frequency identification and other technical means to study how to achieve operational optimization and system stability in practical operation, with extremely high practical value.

TABLE IV. THE KEYWORDS IN INTERNATIONAL LOGISTICS MANAGEMENT RESEARCH FIELD WHICH FREQUENCY IS MORE THAN 1000 TIMES

\begin{tabular}{|c|c|c|}
\hline No. & Keywords & Total Frequency \\
\hline 1 & logistics & 14850 \\
\hline 2 & supply chain & 4950 \\
\hline 3 & reverse logistics & 4345 \\
\hline 4 & supply chain management & 4070 \\
\hline 5 & city logistics & 3685 \\
\hline 6 & optimization & 2750 \\
\hline 7 & sustainability & 2695 \\
\hline 8 & simulation & 2530 \\
\hline 9 & humanitarian logistics & 2310 \\
\hline 10 & genetic algorithm & 1980 \\
\hline 11 & e-commerce & 1925 \\
\hline 12 & internet of things & 1760 \\
\hline 13 & management & 1650 \\
\hline 14 & transportation & 1430 \\
\hline 15 & model & 1265 \\
\hline 16 & green logistics & 1210 \\
\hline 17 & performance & 1210 \\
\hline 18 & rfid & 1210 \\
\hline 19 & closed-loop supply chain & 1155 \\
\hline 20 & logistics management & 1155 \\
\hline 21 & urban logistics & 1155 \\
\hline 22 & vehicle routing & 1155 \\
\hline 23 & biomass & 1100 \\
\hline 24 & remanufacturing & 1100 \\
\hline 25 & uncertainty & 1100 \\
\hline 26 & collaboration & 1045 \\
\hline 27 & facility location & 1045 \\
\hline 28 & risk management & 1045 \\
\hline
\end{tabular}




\section{CONCLUSION}

In connection with 20,555 papers of article, review, and proceeding papers which included from the database of SCIEXPANDED, SSCI, A \& HCI, CPCI-S and CPCI-SSH, the status and hotspot of logistics management are analyzed in this paper. The results of the study show that:

- The global logistics management research papers are fluctuating up.

- The countries and regions that concerned about the logistics research is mainly concentrated in China, the United States, Germany, Britain and so on. Chinese logistics research vitality is in the forefront of the world in recent years, papers published by the United States have the highest citation frequency.

- Beijing Jiaotong University, Wuhan University of Technology, Hong Kong Polytechnic University, University of California System, University of Georgia System and the University of Florida System is the active research unit in this field. However, observed from the average of the published and the average number of cited times, the overall research level and institutional level in the United States, the United Kingdom and Canada are at the forefront both at the national level and at the institutional level.

- The distribution of disciplines is mainly concentrated in the fields of operation and optimization, management, industrial engineering, electrical and electronic engineering, computer information system and so on.

- Logistics research presented as four knowledge groups which is logistics, supply chain, management and technology.

\section{REFERENCES}

[1] Yuan Mei, Present situation and Countermeasures of logistics management in China[J]. Chinese Market.2011(08):35,37(in Chinese)

[2] JunPing Qiu, Bibliometrics [M]. Scientific and Technical Literature Publishing house, 1988. (in Chinese)

[3] ZhiRu Sun, ZhiQiang Zhang. Analysis of The Application of Bibliometrics In Strategic Intelligence Research [J]. Information Theory and Practice . 2008(05) (in Chinese)

[4] LiHua Zuo, A Comparative Study of Word Frequency Analysis and Common Tools [J], Library Journal, 2016.(06) : 38-41. (in Chinese)

[5] Xiang Xiao, ChuanLi Zhou. New Development of Logistics Theory and Its Evaluation [J]. Macroeconomic Research , 2005. (2) :31 -34. (in Chinese)

[6] Hui Fang, DongSheng Zhang. Integrated Development of Green Logistics and Circular Economy[J]. Commercial Economy.2008(10):14 -15. (in Chinese)

[7] DaQiang Chen, Nan Liu, YaPing Liao. Emergency Logistics Material Response Decision Model Based On Cost Modification[J]. Journal of Southeast University (PHILOSOPHY AND SOCIAL SCIENCES EDITION), 2009. (11):67 -70. (in Chinese) 